
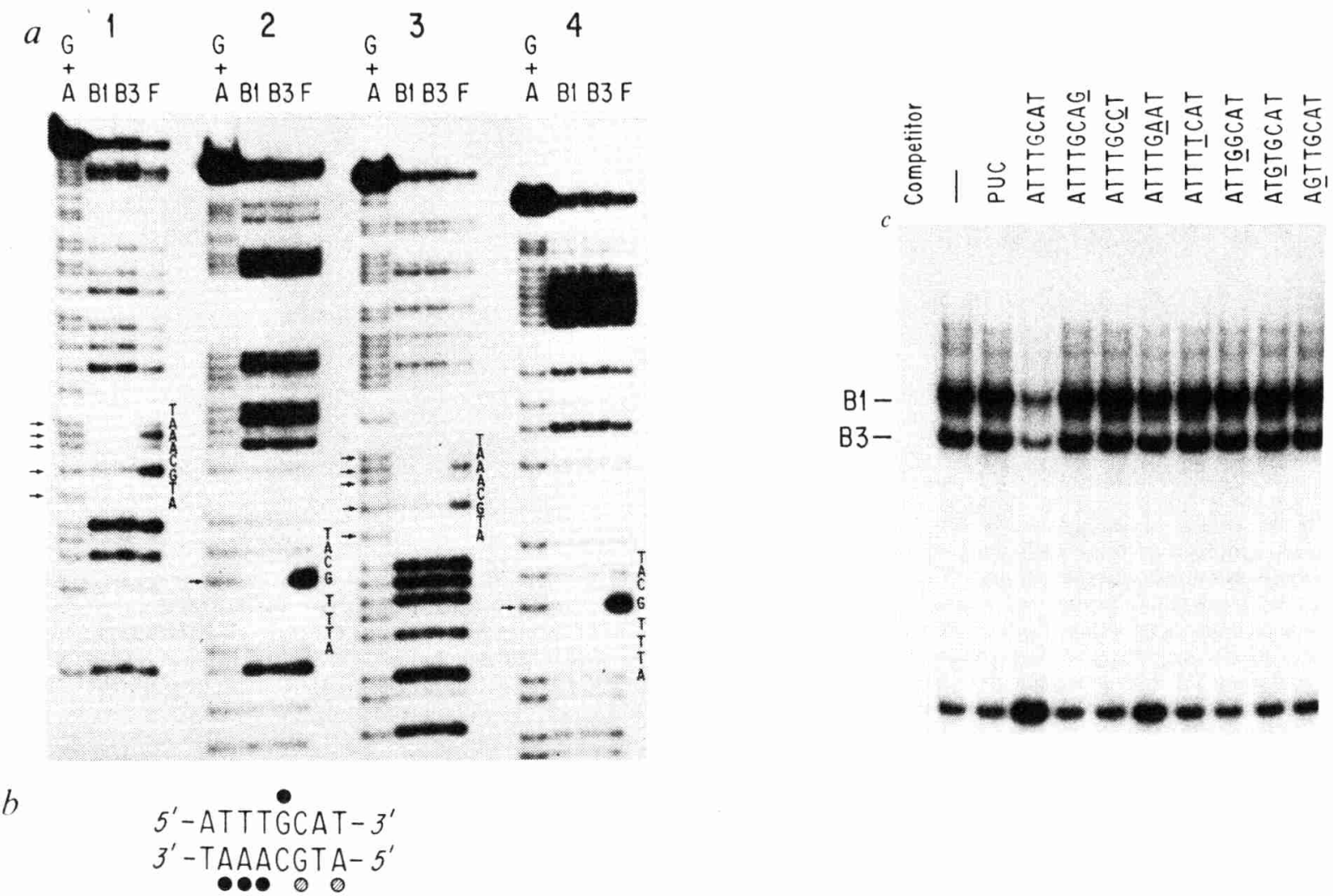

Fig. $3 a$, Methylation interference analysis of octamer binding proteins. Panel 1, H-chain promoter coding strand; panel 2, H-chain promoter noncoding strand; panel $3, \kappa$-chain promoter noncoding strand; panel $4, \kappa$-chain promoter coding strand. Each panel contains a $\mathrm{G}+\mathrm{A}$ reaction ${ }^{26}$ of the probe DNA alongside the cleavage reactions from DNA in complexes B1, B3 and unbound DNA (F). $b$, Scheme of the methylation interference data. Full interference with the binding of the octamer binding proteins is shown as a closed circle and partial interference by a hatched circle. $c$, Fine-specificity analysis of octamer binding proteins.

Methods. DNA fragments of the $\mathrm{H}$-chain promoter from the 17.2.25 gene (position -80 to -18 ; ref. 4 ) or $\kappa$-chain promoter from the $\mathrm{V}_{\kappa} 41$ gene ( $P v u I I-S f a$ NI fragment, ref. 11) were labelled at either $5^{\prime}$ end using a kinase reaction. End-labelled DNA fragments were partially methylated at purine residues by a modification of the method of Maxam and Gilbert ${ }^{26}$ in which the dimethyl sulphate reaction was allowed to proceed for $7 \mathrm{~min}$, then quenched with $1.5 \mathrm{M}$ sodium acetate $(p \mathrm{H} 7.0), 1.0 \mathrm{M}$ 2-mercaptoethanol and $100 \mu \mathrm{g} \mathrm{ml} \mathrm{l}^{-1}$ of poly-d(IC). The methylated DNA was precipitated twice with ethanol, washed with $70 \%$ ethanol, dried and resuspended in $10 \mathrm{mM}$ Tris $p \mathrm{H} 8.0,1 \mathrm{mM}$ EDTA. A five-fold scaled-up binding reaction with the methylated DNA and WEHI-231 nuclear extract was subjected to native polyacrylamide gel electrophoresis (see Fig. 1 legend). After autoradiography of the wet gel, bands B1 and B3 and unbound DNA were cut out. The DNA from each band was electroeluted, bound to DEAE paper as described elsewhere ${ }^{27}$, then eluted from the paper by heating to $68^{\circ} \mathrm{C}$ for $1.5 \mathrm{~h}$ in elution buffer consisting of $20 \mathrm{mM}$ Tris $p \mathrm{H} 8.0,0.1 \mathrm{mM}$ EDTA, $1 \mathrm{M} \mathrm{NaCl}$. The supernatant was extracted twice with phenol and once with chlor oform. After the addition of $1 \mu \mathrm{g}$ carrier transfer RNA, the DNA was precipitated twice with ethanol, rinsed with $70 \%$ ethanol, dried and redissolved in $100 \mu \mathrm{l}$ of $1.0 \mathrm{M}$ piperidine. Reactions were incubated for $40 \mathrm{~min}$ at $90^{\circ} \mathrm{C}$ and lyophilized twice. Equal amounts of radioactivity were subjected to electrophoresis through a $7 \%$ polyacrylamide $/ 8 \mathrm{M}$ urea sequencing gel followed by autoradiography at $-70{ }^{\circ} \mathrm{C}$ with an intensifying screen. $c$, Wild-type or mutant octamer oligonucleotides were cloned into the Bam HI site of the PUC18 polylinker (T.W. et al., manuscript in preparation). DNA fragments containing the wild-type or mutant octamers were excised by HindIII and Eco RI digestion of these plasmids and purified by polyacrylamide gel electrophoresis. Aliquots $(25 \mathrm{ng})$ of these fragments were added as competitors to binding reactions of WEHI-231 nuclear extract with the radiolabelled $\kappa$-promoter fragment probe $(\sim 0.1 \mathrm{ng}$ per reaction $)$ and the products were analysed in the electrophoretic mobility shift assay (see Fig. 1 legend).

nuclear extract. DNA fragments in complexes B1 and B3 as well as the unbound fragments were isolated from a preparative native polyacrylamide gel, cleaved with piperidine and resolved on a sequencing gel (Fig. $3 a$ ). The complexed DNA from the two strands of both the H-chain promoter (Fig. 3a, panels 1,2 ) and the $\kappa$ promoter (panels 3,4 ) was deficient in DNA modified at certain residues within the octamer motif, as indicated by arrows in Fig. $3 a$ and summarized in Fig. $3 b$. Both guanine and, unexpectedly, adenine residues were cleaved in this experiment, although guanine residues reacted more efficiently. Most importantly, though, NF-A1 and NF-A2 had indistinguishable DNA binding sites by this analysis.

The fine specificity of the octamer binding proteins in WEHI231 nuclear extract was analysed further by testing the ability of single transversion mutations in the octamer motif to compete with the wild-type octamer sequence for binding. Synthetic octamer oligonucleotides representing either the wild-type octamer sequence, ATTTGCAT, or transversion mutations at positions 2-8 were cloned into the PUC18 polylinker. Thes DNA constructions also maintained a thymine residue two bas pairs upstream of the initial adenine which is well conserved it immunoglobulin promoters ${ }^{1,3}$. While the wild-type octamer containing fragment competed away B1 and B3 equally wel], the mutant octamer-containing fragments either did not compet at all or, in the case of the mutant ATTTGAAT, competed marginally (Fig. $3 \mathrm{c}$ ). The competition by the wild-type octamer cloned into the PUC18 polylinker demonstrated directly that binding by the octamer-specific proteins does not require any additional sequences within the $\kappa$-promoter region. As expecte from the high degree of conservation of the octamer sequence motif within immunoglobulin promoters in vivo, mutations at the seven positions tested interfered significantly with binding of octamer-specific proteins. Again, this fine-specificity analysis failed to reveal any differences in the DNA binding sites of NF-A1 and NF-A2.

Bacterial lipopolysaccharide (LPS) has pleiotropic effects on 


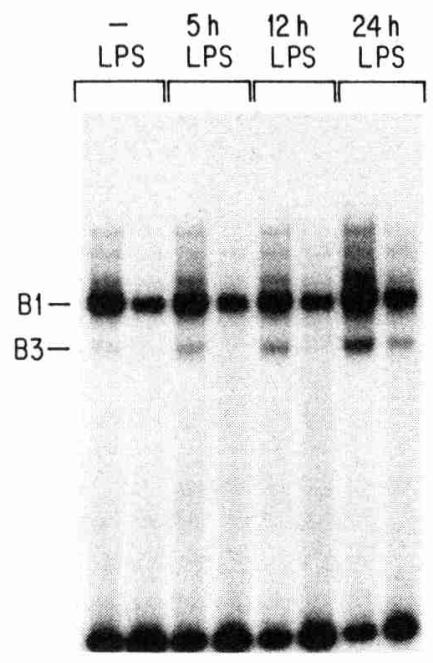

Fig. 4 Induction of the lymphoid-specific octamer binding protein by LPS. $70 \mathrm{Z} / 3$ cells were grown in roller bottles to $3-5 \times 10^{5}$ cells $/ \mathrm{ml}$ in a $1-1$ volume and treated with LPS $\left(10 \mu \mathrm{g} \mathrm{ml}^{-1}\right)$ for $5 \mathrm{~h}$, $12 \mathrm{~h}$ or $24 \mathrm{~h}$, after which nuclear extracts were prepared. These extracts as well as uninduced $70 \mathrm{Z} / 3$ nuclear extract were tested at $8 \mu \mathrm{g}$ and $4 \mu \mathrm{g}$ of protein in the electrophoretic mobility shift assay.

many B-lymphoid cell lines, including the ability to activate immunoglobulin gene transcription ${ }^{12-18}$, and we therefore tested its ability to alter the expression of octamer binding proteins. We prepared nuclear extracts from the LPS-responsive pre-Bcell line $70 \mathrm{Z} / 3$ (ref. 12) before and after treatment with LPS for 5,12 or 24 hours. When equivalent amounts of nuclear extract protein were tested for octamer binding (Fig. 4), NF-A2 increased sixfold following $24 \mathrm{~h}$ treatment by LPS whereas NFA1 was virtually unchanged. When another pre-B-cell line, PD (ref. 19), was treated for $24 \mathrm{~h}$ with LPS, again NF-A2 was induced fourfold by LPS without a corresponding increase in NF-A1 (data not shown). When cycloheximide was added 20 min before a 6.5 -h LPS treatment of $70 \mathrm{Z} / 3$ cells, no induction of NF-A2 was observed (data not shown). Thus, the lymphoidspecific octamer binding protein NF-A2 is preferentially induced in lymphoid cell lines by treatment with LPS and this induction requires new protein synthesis. Because the induction of $\kappa$-chain transcription in $70 \mathrm{Z} / 3$ cells by LPS does not require new protein synthesis ${ }^{17,18}$, an increased amount of NF-A2 is apparently not required for the induction of $\kappa$-chain transcription.

Recent experiments (T.W. et al., manuscript in preparation) demonstrate that a synthetic promoter consisting of an octamer oligonucleotide placed upstream of a TATA box is sufficient for lymphoid-specific transcription. Thus, the octamer motif seems to be necessary ${ }^{2,4,6,8,9}$ and sufficient for lymphoid-specific promoter activity. In apparent contradiction, the human histone H2B gene promoter, which is presumably not tissue-specific, has an octamer positioned 17 base pairs upstream of a TATA box and mutation of the octamer significantly decreases transcription in vitro ${ }^{10}$. A possible explanation is that proteins bound to sequence motifs flanking the histone $\mathrm{H} 2 \mathrm{~B}$ octamer could be required to interact with $\mathrm{NF}-\mathrm{A} 1$ in order to generate an active transcription complex. The $\mathrm{H}$-chain promoter, which contains no other conserved sequence motifs besides the octamer, would then be inactive in non-lymphoid cells. NF-A2 might be able to stimulate transcription in the absence of other DNA binding factors. Thus, the lymphoid specificity of NF-A2 would explain the lymphoid specificity of immunoglobulin promoters.

Recent studies suggest that in lymphoid, but not nonlymphoid, cells the octamer motif contributes to H-chain enhancer activity ${ }^{20,21}$. The $\mathrm{H}$-chain enhancer has been shown to be equivalently active in pre-B, B- and myeloma cell lines ${ }^{22}$, all of which contain NF-A2. Thus, NF-A2 may be involved in the lymphoid-specific activity of the $\mathrm{H}$-chain enhancer as well as in promoter activity.

The discovery of distinct forms of a eukaryotic sequencespecific DNA binding protein raises the possibility that a single transcriptional control sequence is bound by different transacting factors in different tissues and under different conditions of cellular activation. The binding of distinct trans-acting factors to a single regulatory motif could influence the transcriptional activity of a gene in specific tissues.

This work was supported by a grant from the American Cancer Society (IM-355 Q) to D.B. and by grants from NIH (R01GM32467, R01-CA38660), partially from an NCI Cancer Center Support (core) (P30-CA14051) and from NSF (PCM-8200309) to P.A.S. L.S. and H.S. are fellows of the Jane Coffin Childs Memorial Fund for Medical Research. R.S. is a fellow of the Damon Runyon-Walter Winchell Cancer Fund. T.W. is a fellow of the Deutsche Forschungsgemeinschaft.

Received 10 June; accepted 21 July 1986

1. Parslow, T. G., Blair, D. L., Murphy, W. J. \& Granner, D. K. Proc. natn. Acad. Sci. U.S.A. 81, 2650-2654 (1984).

2. Bergman, Y., Rice, D., Grosschedl, R. \& Baltimore, D. Proc. natn. Acad. Sci. U.S.A. 81, $7041-7045$ (1984).

3. Falkner, F. G. \& Zachau, H. G. Nature 310, 71-74 (1984).

4. Grosschedl, R. \& Baltimore, D. Cell 41, 885-897 (1985).

5. Mason, J. O., Williams, G. T. \& Neuberger, M. S. Cell 41, 479-487 (1985).

6. Foster, J., Stafford, J. \& Queen, C. Nature 315, 423-425 (1985).

7. Queen, C. \& Stafford, J. Molec. cell. Biol. 4, 1042-1049 (1984).

8. Gopal, V. T. Shimada, T., Baur, A. W. \& Nienhuis, A. W. Science 229, 1102-1104 (1985).

9. Picard, D. \& Schaffner, W. EMBO J. 4, 2831-2838 (1985)

10. Sive, Hazel, L. Heintz, N. \& Roeder, R. G. Molec cell. Biol (in the press).

11. Singh, H., Sen, R., Baltimore, D. \& Sharp, P. A. Nature 319, 154-158 (1986)

11. Singh, H., Sen, R., Baltimore, D. \& Sharp, P. A. Nature 319, 154-158 (1986)
12. Paige, C. J., Kincade, P. W. \& Ralph, P. J. Immun. 121, 641-647 (1978).

13. Rosenberg, N., Siden, E. \& Baltimore, D. in B Lymphocytes in the Immune Response (eds Cooper, M., Mosier, D., Scher, I. \& Vitteta, E.) 379-386 (Elsevier, Amsterdam, 1979).

14. Perry, R. P. \& Kelley, D. E. Cell 18, 1333-1339 (1979).

15. Alt, F. A., Rosenberg, N., Casanova, R. J., Thomas, E. \& Baltimore, D. Nature 296, 325-331 (1982).

16. Lanier, L. L. J. Immun. 129, 1130-1137 (1982)

17. Nelson, K. J., Kelley, D. E. \& Perry, R. P. Proc. natn. Acad. Sci. U.S.A. 82, 5305-5309 (1985).

18. Wall, R. et al. Proc. natn. Acad. Sci. U.S.A. 83, 295-298 (1986).

19. Lewis, S., Rosenberg, N., Alt, A. \& Baltimore, D. Cell 30, 807-816 (1982)

20. Wasylyk, C. \& Wasylyk, B. EMBO J. 5, 553-560 (1986)

21. Sen, R. \& Baltimore, D. Cell (in the press).

22. Gerster, T., Picard, D. \& Schaffner, W. Cell 45, 45-52 (1986)

23. Pierce, J. H. \& Aaronson, S. A. J. exp. Med. 156, 873-887 (1982).

24. Braun, J. J. Immun. 130, 2113-2116 (1983).

25. Dignam, J. D., Lebowitz, R. M. \& Roeder, R. G. Nucleic Acids Res. 11, 1475-1489 (1983).

26. Maxam, A. \& Gilbert, W. Meth. Enzym. 65, 449-525 (1980).

27. Dretzen, G., Bellard, M., Sassone-Corsi, P. \& Chambon, P. Analyt. Biochem. 112, 295-298 (1981).

\section{A human DNA segment with properties of the gene that predisposes to retinoblastoma and osteosarcoma}

\section{Stephen H. Friend*†, Rene Bernards*, Snezna Rogelj*, Robert A. Weinberg*‡, Joyce M. Rapaport\&, Daniel M. Albert§ \& Thaddeus P. Dryja§}

\author{
* Whitehead Institute for Biomedical Research, Cambridge, \\ Massachusetts 02142, USA \\ $\dagger$ Division of Hematology-Oncology, The Children's Hospital, \\ Dana-Farber Cancer Institute, Department of Pediatrics, \\ Harvard Medical School, Boston, Massachusetts 02115, USA \\ $\ddagger$ Department of Biology, Massachusetts Institute of Technology, \\ Cambridge, Massachusetts 02139, USA \\ \& Department of Ophthalmology, Harvard Medical School and \\ Massachusetts Eye and Ear Infirmary, 243 Charles Street, \\ Boston, Massachusetts 02114, USA
}

The genomes of various tumour cells contain mutant oncogenes that act dominantly, in that their effects can be observed when they are introduced into non-malignant cells ${ }^{1-4}$. There is evidence for another class of oncogenes, in which tumour-predisposing mutations are recessive to wild-type alleles ${ }^{5-7}$. Retinoblastoma is a prototype biological model for the study of such recessive 
oncogenes $^{8}$. This malignant tumour, which arises in the eyes of children, can be explained as the result of two distinct genetic changes, each causing loss of function of one of the two homologous copies at a single genetic locus, $R b$ (refs 9-12), assigned to the q14 band of human chromosome 13 (refs 13-22). Mutations affecting this locus may be inherited from a parent, may arise during gametogenesis or may occur somatically. Those who inherit a mutant allele at this locus have a high incidence of non-ocular, second tumours ${ }^{23}$, almost half of which are osteosarcomas believed to be caused by the same mutation ${ }^{24,25}$. Here we describe the isolation of a complementary DNA segment that detects a chromosomal segment having the properties of the gene at this locus. The gene is expressed in many tumour types, but no RNA transcript has been found in retinoblastomas and osteosarcomas. The cDNA fragment detects a locus spanning at least 70 kilobases (kb) in human chromosome band $\mathbf{1 3 q} 14$, all or part of which is frequently deleted in retinoblastomas and osteosarcomas.

A previous report showed that a $1.5-\mathrm{kb}$ human DNA sequence termed H3-8, selected from a human chromosome 13 lambda phage library ${ }^{26}$, could detect deletions involving $13 q 14$ in 3 out of 37 retinoblastomas ${ }^{27}$. Based on the presumed proximity of the H3-8-homologous sequence to the $R b$ locus, we used chromosome walking techniques to isolate and map $30 \mathrm{~kb}$ of surrounding genomic DNA ${ }^{27}$. DNA derived from human-mouse hybrid cell lines confirms the assignment of selected single-copy fragments generated during the chromosome walk to chromosome 13 .

One of these single-copy fragments, p7H30.7R, recognizes a DNA sequence in the mouse genome and in human chromosome 13. The conservation of this DNA sequence between mice and humans suggested that the cloned fragment contains a coding exon of a gene. We therefore tested the ability of this fragment to hybridize to RNA derived from retinoblastoma cells and adenovirus-12-immortalized human retinal cells ${ }^{28}$, and found that it recognizes a $4.7-\mathrm{kb}$ RNA transcript in the retinal cell line that is not detectable in four retinoblastomas (data not shown), consistent with its association with the $R b$ gene.

We next constructed a cDNA library from RNA of the human retinal line using the bacteriophage cloning vector $\lambda$ gt-11 (ref. 29) and screened this library with the p7H30.7R probe. Several cDNA clones were isolated with similar physical maps. The longest of these, carrying a 4.7-kb insert, was named $\mathrm{p} 4.7 \mathrm{R}$ (Fig. 1) and used to screen cytoplasmic RNA prepared from the adenovirus-12-immortalized retinal cell line, from four retinoblastoma cell lines and from one osteosarcoma cell line. The cDNA probe detects a transcript present in the adenovirusimmortalized retinal cells but not detectable in the tumour cell lines (Fig. 2). Northern blot analysis of poly(A) messenger RNA from adenovirus-immortalized retinal cells yields identical results (data not shown). A 4.7-kb transcript hybridizing to the probe is also detected in other tumour types, including small-cell carcinoma of the lung, neuroblastoma, renal carcinoma and melanoma (Fig. 3), as well as normal adult human retina, spleen and liver (data not shown).

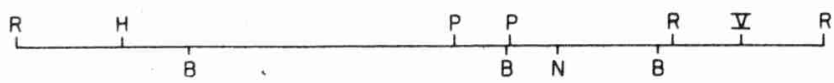

Fig. 1 Physical map of the p4.7R cDNA insert. Restriction enzyme sites are indicated as follows: R, Eco RI; H, HindIII; B, BglII; P, PstI; N, NcoI; V, EcoRV.

Methods. A cDNA library was constructed in $\lambda$ gt11 from adenovirus-immortalized retinal cells ${ }^{28}$ using the technique of Gubler and Hoffman ${ }^{29}$. This technique involved oligo(dT) priming and second-strand synthesis with DNA polymerase I and RNAse $\mathrm{H}$. The double-stranded cDNA was methylated at internal EcoRI sites, ligated to EcoRI linkers, and size-selected for cDNA

fragments $>2.3 \mathrm{~kb}$ by agarose gel electrophoresis. Bar, $1 \mathrm{~kb}$.

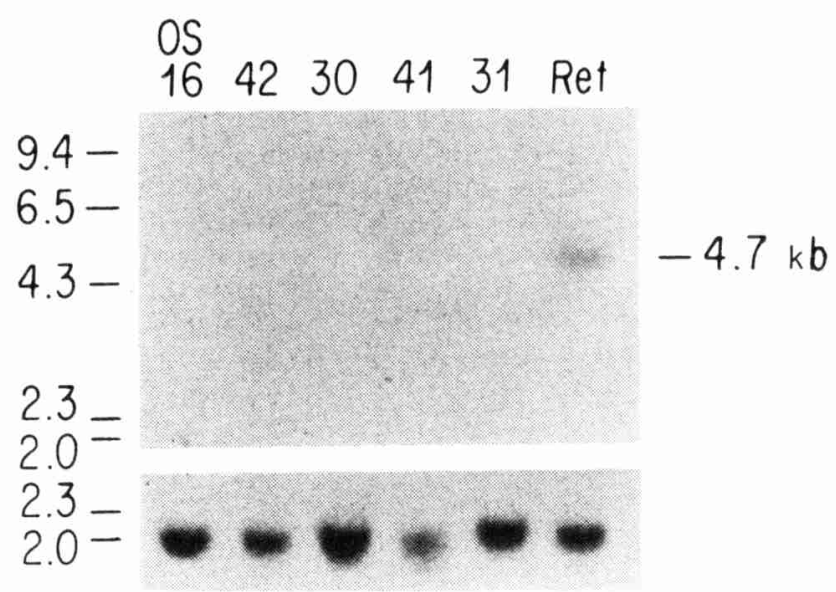

Fig. 2 Northern blot analysis of RNA isolated from retinal and osteosarcoma cells. RNA $(20 \mu \mathrm{g})$ was loaded from osteosarcoma tumour No. 16; four retinoblastomas: Nos 42, 30 (Y-79, ref. 30), 41 (WERI-1, ref. 31) and 31; and the adenovirus-12-transformed retinal cells (ref. 28), $a$, Samples probed with p4.7R insert. The transcript detected in the retinal cells is $4.7 \mathrm{~kb}$ in size. Molecular mass markers indicated on the left. $b$, After washing the filter, it was rehybridized with a probe derived from the rat tubulin locus ${ }^{32}$ Methods. Total cytoplasmic RNA was isolated using the NonidetP-40 extraction technique, resolved by electrophoresis through a $1 \%$ agarose-formaldehyde gel, and transferred onto nitrocellulose as described by Schrier et al. ${ }^{33}$. Radiolabelling of probes was performed using the random-primer method ${ }^{34}$.

The ubiquitous presence of this transcript contrasts to its apparent absence in the retinoblastoma and osteosarcoma specimens. Indeed, its absence in retinoblastomas and osteosarcomas might be central to the pathogenesis of these two tumour types. Specifically, our data are consistent with a close association between the DNA template of the $4.7-\mathrm{kb}$ transcript and the $R b$ gene. Further support of this association requires analysis of the tumour DNA sequences recognized by the $\mathrm{p} 4.7 \mathrm{R}$ probe.

The probe allowed a survey of a $70-\mathrm{kb}$ chromosomal region. Preliminary mapping was performed by ordering the genomic HindIII restriction endonuclease fragments present in normal human DNAs that are reactive with this probe (Fig. 5). Because this map was generated by use of a cDNA probe, it includes only genomic fragments that specify sequences found in exons. We made similar maps of the fragments generated by TaqI and $X b a I$ (data not shown). All the DNA fragments included in this map and used in the following studies were assigned to chromosome 13 (data not shown).

The p0.9R probe, the subclone containing the $0.9 \mathrm{~kb}$ EcoRI/EcoRI fragment deriving from the right end of p4.7R, reacts with three HindIII fragments $(1.2,1.5$ and $5.8 \mathrm{~kb})$ that occur in genomic lambda phage clones of this region ${ }^{27}$ and are included in Fig. 5. This probe reacts with a low copy-number repeat sequence present in the human genome (Fig. $4 b$ ). The following analyses were possible despite the detection of these repeated sequences.

DNA was isolated from a set of tumours from unrelated patients, each of which was thought to arise because of inactivating mutations at the $R b$ locus. The set consisted of 40 retinoblastomas (including tumours from patients with sporadic and familial disease), 8 osteosarcomas and 2 undifferentiated tumours of unknown cellular origin arising in patients with hereditary retinoblastoma.

Screening of tumour DNA samples using Southern blot analysis and probes derived from $\mathrm{p} 4.7 \mathrm{R}$ reveals three types of deviant restriction-fragment patterns: totally absent fragments, reflecting apparent homozygous deletions; under-represented fragments, reflecting apparent heterozygous deletions; and fragments of altered size, reflecting partial deletion, sequence rearrangement 


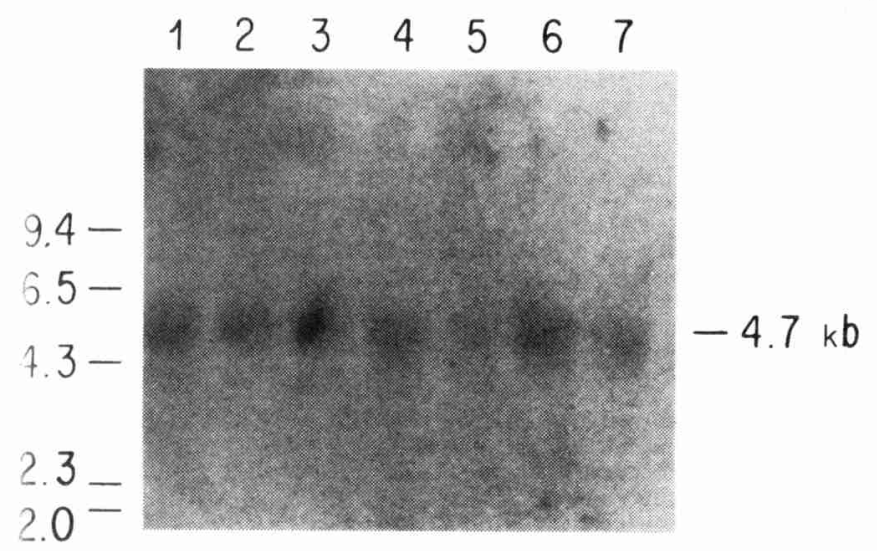

Fig. 3 Northern blot analysis of RNA isolated from various tumour cell lines. RNA was prepared and loaded as in Fig. 2. Lane 1, LX-1 (small-cell carcinoma of the lung); lane 2, SKNSH (neuroblastoma); lane 3, CAKI-1 (renal clear cell carcinoma); lane 4, MEL-5 (melanoma); lane 5, SKNMC (neuroblastoma); lane 6 , SKRC-2 (renal carcinoma); lane 7, ACHN (renal adenocarcinoma). ${ }^{32}$ P-labelled $\mathrm{p} 4.7 \mathrm{R}$ insert was used as a probe. Positions of molecular mass markers are indicated on the left.

or alteration of a restriction endonuclease recognition site. At least $30 \%$ of the tumour DNAs have one of these abnormalities. In contrast, analysis of leukocyte DNA from 18 normal individuals shows a uniform pattern of restriction fragments, hence the abnormal patterns of fragments probably do not represent frequently occurring, incidental polymorphisms.

Homozygous deletion of restriction fragments in six of the tumours are shown in Fig. 4. DNA from tumours passaged in tissue culture (for example, No. 41) or in nude mice (for example, OS-15) lack certain restriction fragments normally detected by the probe. DNA isolated directly from surgical specimens (for example, Nos 9, 44 and 3 ) has a low concentration of certain normal restriction fragments, amounting to $<10 \%$ the normal diploid dose. These faint bands result from small numbers of normal cells from adjacent tissue contaminating tumour cells with homozygous deletions. In some tumours (Nos 28, 3 and 43) deletions also result in the appearance of HindIII fragments of novel length.

The extent of the deletions present in these tumours is mapped in Fig. 5, and is similar to results obtained with TaqI or XbaI (data not shown). Most of the deletions, including those present in tumours $41,9,44,28$ and 3 , have an endpoint in the transcription unit defined by the probe and extend apparently leftwards beyond this unit (Fig. 5). These deletions may have signified that a gene to the left of this transcription unit was the target of the oncogenic mutations. However, we have found two instances in which the deletions involve only internal regions of this unit, leaving adjacent DNA unaffected.

The first of these two cases concerns retinoblastoma tumour No. 43, which carries a deletion involving DNA sequences that map entirely within the confines of the transcription unit defined by the probe (Figs 4,5 ). This deletion is present in a heterozygous state. Thus, Fig. 4 shows that two restriction fragments created by HindIII cleavage (of 2.05 and $6.2 \mathrm{~kb}$ ) and which map to the left part of this genomic region are present in normal, diploid amounts. Similarly, fragments found at the right end (HindIII : 1.5, 1.2 and $5.8 \mathrm{~kb}$ ) are also found in normal dosage. In contrast, fragments from the centre of this region (HindIII : 9.4, 5.3, 7.4 and $4.5 \mathrm{~kb}$ ) are present in about half the normal amounts. A novel HindIII fragment of $10.0 \mathrm{~kb}$ arises from the partial deletion of one copy of the normally present $9.4-\mathrm{kb}$ HindIII fragment.

The second instance of an internal deletion involves an osteosarcoma, OS-15, which arose in a patient who had no retinoblastoma or family history of retinoblastoma. The extent

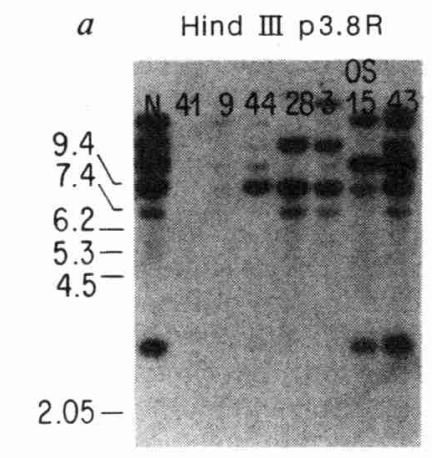

$b \quad$ Hind III p $0.9 R$

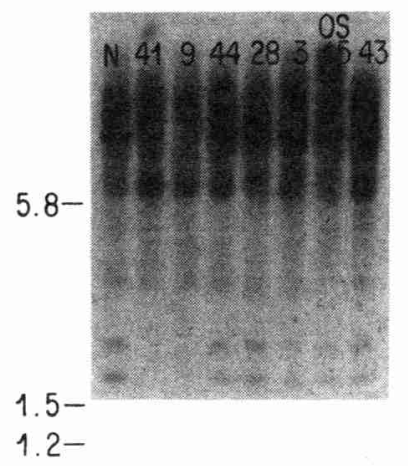

Fig. 4 Southern blot analysis of retinoblastoma, osteosarcoma and normal DNAs probed with subclones of p4.7R (Fig. 1). The first lane $(\mathrm{N})$ contains lymphocyte DNA from a normal, healthy human. The adjacent lanes have DNA from the following tumours: retinoblastoma No. 41 (WERI-1, ref. 31); retinoblastoma No. 9; retinoblastoma No. 44; retinoblastoma No. 28 ; retinoblastoma No. 3; osteosarcoma OS-15 (ref. 24); and retinoblastoma No. 43. DNA ( $4 \mu \mathrm{g}$ per lane) was digested with HindIII. $a$, Probed with a $3.8-\mathrm{kb}$ EcoRI/ EcoRI subcloned fragment of p4.7R (see Fig. 1). b, Probed with a 0.9-kb EcoRI/ EcoRI subcloned fragment of p4.7R (Fig. 1). Methods. DNA isolation, restriction endonuclease digestion of DNA samples, agarose gel electrophoresis, Southern blotting and hybridization were all performed according to standard methods. Radiolabelling was performed using the random-primer method ${ }^{34}$.

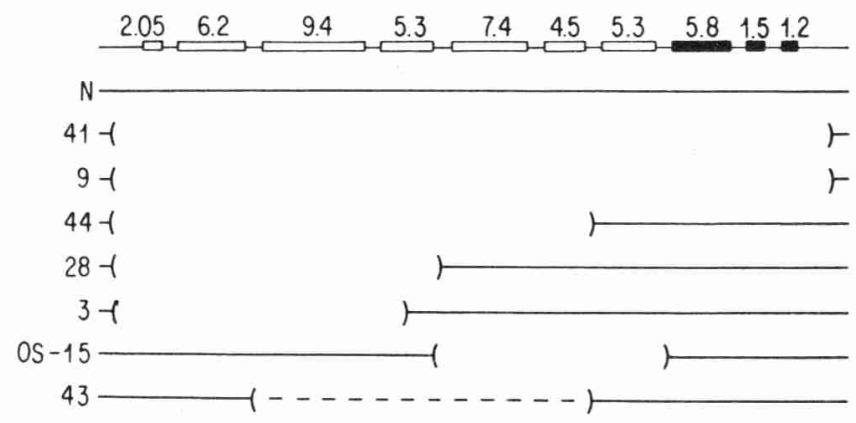

Fig. 5 Schematic representation of deletions in the genomic DNA from six retinoblastomas and an osteosarcoma. The genomic HindIII fragments detected by the 3.8- and 0.9-kb EcoRI fragments, denoted by open and closed bars, respectively (see Fig. 4), are shown at the top according to their relative positions in the genome and labelled with sizes in kilobases. Normal and tumour DNAs, numbered as in Fig. 4, have solid lines where both copies of a given genomic fragment are present. Dotted line between brackets,

heterozygous deletion; open brackets, homozygous deletion.

of the deletion, which was homozygous in this case, is indicated in Figs 4 and 5 by the absence of the 7.4- and $4.5-\mathrm{kb}$ HindIII fragments. The internal deletions in tumours 43 and OS-15 suggest that the chromosomal segment recognized by $\mathrm{p} 4.7 \mathrm{R}$ is the common target for these mutations.

Note that the genetic origin of the deletions found in 3 of the 50 tumours has been shown previously to be somatic in two cases and germinal in the third. Therefore, these deletions are not inherited polymorphisms ${ }^{27}$. These data, taken together with the internal deletions described above, strongly suggest that this segment is the carrier of the DNA sequences of the $R b$ gene.

Earlier work shows the absence of a detectable transcript in five tumours from our set (Fig. 2). The apparent absence of transcript from these tumours is presumably important in their aetiology and lesions affecting the DNA of this gene must be frequently involved in the inactivation of expression. Accordingly, we examined the DNA of the four retinoblastomas that 
lacked detectable transcript. One of these has a homozygous deletion of the region detected by p4.7R (tumour 41, Fig. 4). However, the other three retinoblastomas have no abnormality. We deduce that tumours having no grossly aberrant genomic fragments may nevertheless have mutations affecting this region. A precedent for the role of small structural changes as a cause of gene inactivation is provided by studies of other human disease loci in which gross changes in DNA structure represent the minority of mutations responsible for loss of function ${ }^{35}$.

Fifteen years ago, Knudson provided a theoretical basis for retinoblastoma tumorigenesis by suggesting that minimally two genetic events are required to trigger tumour development ${ }^{8}$. These events may represent loss-of-function mutations at the retinoblastoma locus, and other tumours may arise by a similar mechanism via recessive mutations at other $\operatorname{loci}^{36}$. Evidence in support of this theory comes from the study of a diverse group of tumours, including Wilms tumour, hepatoblastoma, rhabdomyosarcoma ${ }^{37}$, uveal melanoma ${ }^{38}$ and bladder cell carcinoma $^{39}$. A recessive oncogene from the fruitfly with tumourinhibiting properties has recently been isolated ${ }^{40}$.

We have isolated a human cDNA sequence apparently representing one of this class of genes. This $\mathrm{cDNA}$ detects a chromosomal segment having properties of the $R b$ gene which maps to human chromosome $13 \mathrm{q} 14$. Part or all of the sequence is deleted in some retinoblastomas and osteosarcomas, and some of the deletions affect only an internal region of the segment.

We next seek to determine whether some malignant properties of retinoblastoma and osteosarcoma cells can be reverted on introduction of cloned sequences thought to represent the $R b$ gene. The isolation of the $\mathrm{p} 4.7 \mathrm{R}$ clone should also provide a powerful diagnostic reagent that will help to determine whether a particular retinoblastoma stems from an inherited genetic lesion or from a new mutation of somatic or germinal origin. Furthermore, the variable expression of this gene in different tumours may provide a new method by which tumours are classified.

We thank Sang-Ho Park, John E. Price, Frederick P. Li, Raju Chaganti, Jennifer M. Joyce and Theresa Dryden for technical assistance; David Page, Michael Gilman, Cori Bargmann and David Stern for helpful comments; R. T. M. J. Vaessen and A. J. van der Eb for the gift of the adenovirus-transformed retinal cells; Dr Samuel Lett in the Department of Genetics for efforts in developing the H3-8 probe; Robert Petersen, David Walton, Johan Zwaan, Charles Regan, Ted Sery, Webster Cavenee, William Benedict, Brenda Gallie, Raju Chaganti, Allen Goorin, David Abramson, James Epstein, Steven Blattner and Z. Nicholas Zakov for help in obtaining tumour specimens. R.B. is a fellow of The Netherlands Organisation for the Advancement of Pure Research; S.R. is an NIH fellow; R.A.W. is an American Cancer Society Research Professor. Supported by NIH grants EY05321 and CA39826, a grant from the American Business Foundation for Cancer Research, and by gifts from the Wytrzes, Friedman, Smith and Gorfinkle families to the Taylor R. Smith Laboratory of the Massachusetts Eye and Ear Infirmary.

Received 24 July; accepted 19 August 1986.

1. Bishop, J. M. Cell 42, 23-28 (1985).

2. Land, H Parada, L \& Weinberg, R. A. Science 222, 771-778 (1983).

3. Heldin, C. H. \& Westermark, B. Cell 37, 9-20 (1984)

4. Sporn, M. B. \& Roberts, A. B. Nature 313, 745-747 (1980).

5. Klein, G. \& Klein, E. Nature 315, 190-195 (1985).

6. Green, A. R. \& Wyke, J. A. Lancet ii, 475-477 (1985).

7. Knudson, A. G. Jr Cancer Res. 45, 1437-1443 (1985).

8. Knudson, A. G. Jr Proc natn. Acad. Sci. U.S.A. 68, 820-823 (1971).

9. Múrphree, A. L. \& Benedict, W. F. Science 223, 1028-1033 (1984).

10. Godbout, R. et al. Nature 304, 451-453 (1983).

11. Cavenee, W. K. et al. Nature 305, 779-784 (1983).

12. Dryja, T. P. et al. N. Engl. J. Med. 310, 550-553 (1984).

13. Sparkes, R. S. et al. Science 208, 1042-1044 (1980).

14. Yunis, J. J. \& Ramsey, N. Am. J. Dis. Child. 132, 161-163 (1978)

15. Vogel, F. Hum. Genet. 52, 1-54 (1979).

16. Motegi, T. Hum. Genet. 61, 95-97 (1982)

17. Balaban, G. et al. Cancer Genet. Cytogenet. 6, 213-221 (1982)
18. Chaum, E. et al. Cytogenet. Cell Genet. 38, 82-91 (1984).

19. Sparkes, R. S. et al. Science 219, 971-973 (1983)

20. Connolly, M. J. et al. Hum. Genet. 65, 122-124 (1983).

21. Mukai, S. et al. Am. J. Ophthalmol. 97, 681-685 (1984).

22. Halloran, S. B. et al. Arch. Ophthalmol. 103, 1329-1331 (1985).

23. Abramson, D. H. et al. Ophthalmology 91, 1351-1355 (1984).

24. Dryja, T. P. et al. Am. J. hum. Genet. 38, 59-66 (1986).

25. Hansen, M. F. et al. Proc. natn. Acad. Sci. U.S.A. 82, 6216-6220 (1985).

26. Lalande, M. et al. Cancer Genet. Cytogenet. 13, 283-295 (1984).

27. Dryja, T. P. et al. Proc. natn. Acad. Sci. U.S.A. (in the press).

28. Vaessen, R. T. M. J. et al. EMBO J. 5, 335-341 (1986).

29. Gubler, U. \& Hoffman, B. Gene 25, 263-269 (1983).

30. Reid, T. W. et al. J. natn. Cancer Inst. 53, 347-360 (1974).

31. McFall, R. C., Sery, T. W. \& Makadon, M. Cancer Res, 37, 1003-1010 (1977).

32. Lemischka, I. R. et al. J. molec. Biol. 150, 101-120 (1981).

33. Schrier, P. I. et al. Nature 305, 771-775 (1983).

34. Feinberg, A. P. \& Vogelstein, B. Analyt. Biochem. 132, 6-13 (1983).

35. Kunkel, L. M. et al. Nature 322, 73-77 (1986).

36. Comings, D. E. Proc, natm. Acad. Sci. U.S.A. 70, 3324-3328 (1973).

37. Koufos, A. et al. Nature 316, 330-334 (1985).

38. Mukai, S. \& Dryja, T. P. Cancer Genet. Cytogenet. 22, 45-53 (1986).

39. Fearon, E. R et al Nature 318, 377-380 (1985).

40. Mechler, B. M., McGinnis, W. \& Gehring, W. J. EMBO J. 4, 1551-1557 (1985)

\section{Isolation of candidate cDNAs for portions of the Duchenne muscular dystrophy gene}

\author{
Anthony P. Monaco*†, Rachael L. Neve*†, \\ Chris Colletti-Feener*, Corlee J. Bertelson*, \\ David M. Kurnit* \& Louis M. Kunkel*†
}

* Division of Genetics, Mental Retardation Program, Department of Pediatrics, Harvard Medical School, The Children's Hospital, Boston, Massachusetts 02115, USA

† The Program in Neuroscience, Harvard University, Cambridge, Massachusetts 02138, USA

Duchenne muscular dystrophy (DMD) and the less severe Becker muscular dystrophy (BMD) are human X-linked muscle-wastiig disorders that have been localized to the band $\mathrm{Xp21}$ by genetic linkage analysis ${ }^{1-9}$ and cytologically detectable abnormalities ${ }^{10-i 2}$. A cloned DNA segment, DXS164 (or pERT87), has been shown to detect deletions in the DNA of unrelated DMD and BMD males ${ }^{13-15}$. Here we present the nucleotide sequence of two highly conserved DNA fragments from the DXS164 locus and the ir homologous sequences from the mouse $\mathbf{X}$ chromosome. One of the human conserved segments hybridized to a large transcript in $R N A$ isolated from human fetal skeletal muscle and was used to isola cDNA clones which cover approximately $10 \%$ of this transcript. The cDNA clones map to Xp21 and hybridize with a minimum of eight small regions that span 130 kilobases $(k b)$ of the DXS164 locus. These expressed sequences are candidates for portions of the gene responsible for both DMD and BMD.

The cloned DNA of the DXS164 locus was expanded from $137 \mathrm{~kb}^{15}$ to $220 \mathrm{~kb}$ of contiguous DNA in a total of nine bidire tional chromosome walks made in human partial digest pha libraries. A schematic restriction map for the enzymes EcoR: HindIII, and KpnI is presented in Fig. 1 for the entire length. Given that the DXS164 locus was found to be deleted in patien is with DMD and BMD ${ }^{14,15}$ and was centrally located with respect to mutations which give rise to the disease ${ }^{15}$, we searched for regions that might be transcribed. As an alternative approach to Northern blot analysis of each individual DNA subclone from the DXS164 locus, a systematic search was undertaken for nucleotide sequence conservation across species. Approximately 50 unique subclones from the DXS164 locus were use individually as hybridization probes on Southern blots of Hin dIII digested DNA isolated from cebus, bovine, mouse, hamster and chicken. Most unique subclones were found to

$\ddagger$ To whom correspondence should be addressed 


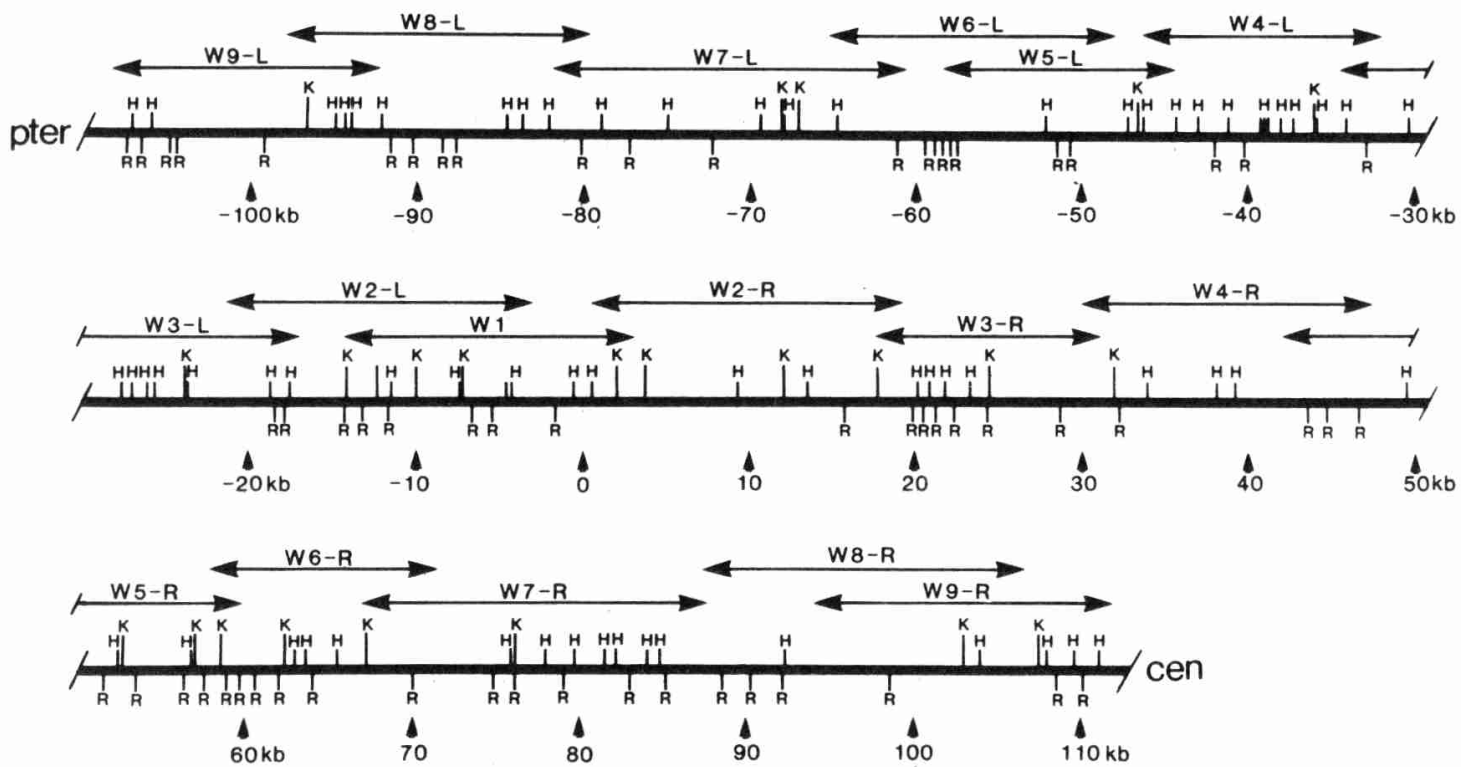

Fig. 1 Schematic restriction map of the DXS164 (pERT87) locus. The heavy line indicates the points of cleavage for the restriction enzymes EcoRI (R), HindIII (H) and KpnI (K). The coordinates show the distance in kilobases starting at zero for the position of the original pERT87 clone $^{13-15}$. The terminus of the short arm of the X-chromosome is indicated on the left-hand side of the map and the centromere on the right as positioned by deletion analysis ${ }^{15}$. Lines with arrowheads represent overlapping cloned DNA segments isolated from human recombinant phage libraries ${ }^{14}$. Numbers on these lines detail the walk number and direction (left or right from zero). Phage clones with human inserts were plaque purified and DNA was isolated ${ }^{28}$ and restriction mapped. Phage DNA digests were subcloned into the plasmid vectors pBR322 ${ }^{29}$ pUC1 $8^{30}$ and Blue-Scribe (Stratagene). Subclones were restriction mapped further with the enzymes $X b a$ I, BglII, PstI and Bam HI, to identify small fragments free of human repetitive elements. All unique sequence subclones were tested for human X-chromosome localization as previously described ${ }^{14}$. Methods and conditions described elsewhere ${ }^{2,14}$.

Fig. 2 Cross-species homology of two subclones from the DXS164 locus. Dark black line, the $220 \mathrm{~kb}$ of cloned DNA of the DXS164 locus. Markers for every $50 \mathrm{~kb}$ are positioned across the map as well as two conserved subclones, pERT87-25 and pERT87-4, which are $70 \mathrm{~kb}$ apart. Two areas defined by deletion breakpoint analysis that may be important to the expression of the DMD gene ${ }^{15}$ are indicated below the schematic of the DNA map. Autoradiograph lower left, hybridization analysis of subclone pERT8725 (a 1.95 Eco RI/ HindIII fragment) to specific HindIII restriction fragments in $1.5 \mu \mathrm{g}$ of the following DNA samples: bovine DNA (lane $1)$, cebus monkey DNA (2, provided by A. Scott), human male DNA (3), human X-chromosome DNA in a hamster DNA background (4, G89, ref. 32), hamster DNA alone (5, provided by J. Kang), mouse DNA (6, RAG cell line provided by G. Bruns) and chicken DNA (7). Radiolabelled HindIII digested $\lambda$ DNA (8) was used as a size marker (2.0, 2.3, 4.4, 6.6, 9.4 and 23.5 kb). Autoradiograph lower right, hybridization of subclone pERT87-4 (2.3 kb of pooled Xba I fragments) to several HindIII fragments in cebus monkey DNA (1), and a single HindIII fragment in bovine DNA (2), mouse DNA (4) and a human X-chromosome band at $4.2 \mathrm{~kb}$ on a hamster DNA background ( 9.0 and $2.7 \mathrm{~kb}$ bands) (G89, lane 6). pERT87-4 did not hybridize to chicken DNA (3). Radiolabelled HindIII digested $\lambda$ DNA is shown (5). Both Southern blots were done at high stringency (hybridize in $50 \%$ formamide, $4 \times \mathrm{SSC}$ at $45^{\circ} \mathrm{C}$; wash at $55^{\circ} \mathrm{C}$ for $1 \mathrm{~h}$ in $0.1 \%$ SDS and $0.1 \times$ SSC). Negative hybridization results with both pERT87-25 and pERT87-4 for DNA isolated from Drosophila melanogaster (provided by W. Bender), Caenorhabditis elegans (provided by S. Wood) and lobster (provided by H. Potter) are not shown.

hybridize to cebus primate DNA, and several hybridized weakly to bovine DNA. Only two subclones, pERT87-4 and pERT87-25, exhibited hybridization to all mammalian DNA samples tested (Fig. 2). Subclone pERT87-4 is from $\mathrm{a}_{4} 4.2 \mathrm{~kb}$ HindIII fragment located at $-10 \mathrm{~kb}$ in the DXS164 locus, and hybridizes to specific HindIII fragments in mammalian but not chicken DNA. This subclone lies inside the $10 \mathrm{~kb}$ region of deletion overlap found in most deletions analysed at the DXS164 locus ${ }^{15}$. Subclone pERT87-25 is from a $1.95 \mathrm{~kb}$ Eco RI/HindIII fragment located at $-82 \mathrm{~kb}$ in the DXS164 locus, $70 \mathrm{~kb}$ toward the terminus from pERT87-4. It hybridizes to specific HindIII fragments in DNA from all mammals tested and strongly to chicken DNA. Subclone pERT87-25 is deleted from the DNA of two DMD males whose deletion breakpoints occur further toward the terminus ${ }^{15}$. 